\title{
La pronunciación de la diferencia entre lo filosófico, lo pedagógico y lo literario
}

\author{
Carlos Skliar* \\ http://dx.doi.org/10.1590/0103-7307201507605
}

\section{Resumen}

Se ha vuelto habitual el hablar sobre las diferencias como si se tratara de un atributo esencial de ciertos sujetos o de ciertas identidades peculiares. Los escenarios educativos que proclaman nociones tales como la igualdad, la inclusión y la diversidad asumen una posición de proximidad/distanciamiento con res* CONICET; Facultad Latinoamericana de Ciencias Sociales FLACSO, Buenos Aires, Argentina. skliar@flacso.org.ar

pecto a la experiencia singular de estar en relación entre diferencias. Sus lecturas están atravesadas por fuertes componentes de normalización y de regulación jurídica. Entonces ¿qué lectura puede hacerse presente a la hora de contar la multiplicidad sin final de las diferencias al interior de lo educativo? Una lectura literaria que permita, tal vez, ir más allá de las imágenes desteñidas que confunden las diferencias con sujetos pensados como diferentes y que, quizá, revele la complejidad y el azar de las acciones y las experiencias pedagógicas.

Palabras clave: diferencias, Filosofía, Pedagogía, literatura 


\title{
The pronunciation of the difference between the philosophical, pedagogical and literary
}

\begin{abstract}
It has become customary to talk about the differences as if they were essential attribute of certain subjects or certain peculiar identities. Educational scenarios that proclaim notions such as equality, inclusion and diversity assume a position of proximity/distance with respect to the unique experience of being in relationship between differences. His readings are crossed by strong components standardization and legal regulation. So: What reading can be present at the time of thinking the multiplicity of differences within Education? A literary reading that allows, perhaps, go beyond faded images that confuse the differences with subjects thought of as different and, perhaps, reveal the complexity and randomness of actions and educational experiences.
\end{abstract}

Keywords: differences, Philosophy, Pedagogy, literature 


\section{Introducción. La diferencia perdida (y reencontrada) entre la pedagogía, la filosofía y la literatura}

En su pronunciación latina la palabra 'diferencia' (differentia) supone, al mismo tiempo: separación, discriminación, disimilitud, desemejanza, distancia, una distinción, la enunciación de lo distinto ${ }^{1}$. Todos esos sentidos provienen de la raíz de la palabra diferencia, pero no se encuentran necesariamente en su sentido interior.

También podríamos decir que se trata de una palabra relacional - no de esencias ligadas a sujetos específicos - y que se pronuncia en el espacio y la distancia que permanece, siempre, entre dos singularidades. Hay diferencia, no se es diferencia. Cuando se atribuye una diferencia a un sujeto diferente la conversación se interrumpe porque suele ser culposa y humillante. $Y$ a pesar de que hoy se celebre la diferencia y se insista en que todos somos diferentes, conviene volver a pensar en la 'diferencia' por fuera de la obsesión de traducirla en términos de 'sujetos diferentes'.

En un estudio que realizamos con maestros sobre los sentidos de la diferencia implicados en las prácticas pedagógicas al interior de diferentes instituciones educativas, encontramos que por lo general se identifica la diferencia como desvío, como negatividad, como desigualdad y como lo opuesto a la normalidad. En este estudio, mientras la diversidad era considerada una "oportunidad", la diferencia era vista como un "problema a resolver”. Además, había una divergencia de sentidos entre los maestros de educación especial -que entendían la diferencia en términos de sujetos especiales- y los maestros de educación regular-que la comprendían en relación a la pobreza, la inmigración, etcétera.² (Skliar \& Dussel, 2011).

$Y$ es que hay una indecisión o una confusión habitual en los escenarios educativos, que se origina en el instante en que las diferencias se hacen presentes y son nombradas. Ocurre que en el acto mismo de enunciar la diferencia sobreviene una derivación hacia otra pronunciación totalmente diferente: los 'diferentes', haciendo alusión a todos aquellos que no pueden ser vistos, ni pensados, ni sentidos, ni al fin educados, por culpa de esa curiosa y vanidosa percepción de lo homogéneo -homogeneidad de lenguas, de aprendizajes, de cuerpos, de comportamientos, de lenguas y, así, hasta el infinito-. En síntesis: parece ser que lo que existe al interior de la palabra diferencia es un conjunto siempre indeterminado, siempre impreciso, de sujetos definidos como diferentes.

1. Todas las referencias a las expresiones latinas presentes en este texto provienen del Diccionario Latino-Español. Barcelona: Publicaciones y Ediciones Spes, 1950.

2. Nesta Revista, nas referências curtas que acompanham as citações no texto, apenas a letra inicial dos nomes dos autores deve receber maiúscula, conforme as normas da APA. 
Puede que sea necesaria la pregunta ¿qué es la diferencia?, pero a poco que entramos en ella, aparece una doble encrucijada: o bien son los diferentes o, en otro sentido, sólo se responde por la identidad. Veiga-Neto da a entender que cualquier pregunta directa sobre la diferencia es mucho menos interesante de lo que aparenta ser:

En primer lugar, una pregunta como “¿cuál es la diferencia?" remite a la vieja pregunta “¿qué es eso?", revelando así el encantamiento en que nos dejamos aprisionar por el propio lenguaje con que lidiamos y contestamos preguntas. En segundo lugar, por ser radicalmente contingentes, las formas de vida no se repiten y están cambiando constantemente, de modo que tal vez lo máximo que se pueda decir sea simplemente: la diferencia es el nombre que damos a la relación entre dos o más entidades (Veiga-Neto, 2009, p. 122).

La diferencia está ahí, no en una cosa, en un fenónemo, en un concepto, en un sujeto particular. La traducción que traiciona el sentido relacional de la diferencia tranformándolo en alguien definido como sujeto diferente puede ser llamada de diferencialismo: no tiene que ver con la cosa o persona vista sino con quien ve y nombra. Sugiere una relación con otro y con lo otro, sí, pero es una relación fantasmagórica y violenta; violenta porque se reduce en el otro la incapacidad de mirar "entre"; porque disimula lo que el uno no es capaz de mirar en sí mismo; porque, al fin de cuentas, impide que el otro sea visto como cualquier otro y, de ese modo, separa, abandona, pone bajo sospecha la idea de que el otro sea tan humano como el uno.

Imagen fantasmagórica, porque el diferente no existe, es inexistente. La descripción que se hace del diferente jamás coincide con nadie, no hay allí transparencia, sino prejuicio: los diferentes serían los incapaces a capacitar, los incompletos a completar, los carentes a dotar, los salvajes a civilizar, etc. La imagen del diferencialismo se vuelve, así, bien nítida: no es otra cosa que un dedo que apunta, que acusa directamente a todo aquello que se cree que falta o hace falta, a lo que se entiende como ausencia, a lo que se configura como anormal.

\section{La lectura filosófica de la diferencia}

Hubo que esperar a Nietzsche para que la filosofía, o parte de ella, dejara de pensar en la diferencia como lo opuesto y lo negativo de la identidad, para que su escritura irrumpiera contra la lógica de la identidad, esa lógica que supone que primero está la afirmación de un ser único, la entidad, el sujeto consciente, la afirmación de lo uno, 
la tiranía de lo mismo, y luego el otro, lo otro, lo demás, en fin, el universo.

En la continuidad de esa tradición filosófica y, sobre todo, a partir de lo que se ha dado en llamar como filosofía de la diferencia, Deleuze toma distancia de la identidad, de la representación y de la mismidad y, considera la diferencia en sí misma, por sí misma, a través de su propio movimiento de diferir.

Por tanto, la diferencia no estaría en relación con dos puntos que, de acuerdo con un cierto principio de identidad, se diferencian. La diferencia tendría más que ver con el entre-medio, y no como una supuesta oposición entre dos términos, dos entes, dos conceptos o dos cosas. Así, la diferencia es un signo de lo imprevisible, que hace pensar en el devenir y remite al acontecimiento. La idea de diferencia de Deleuze no remite a un sujeto, no lo identifica como tal. Y no se relaciona tampoco con la idea del diferente, de los diferentes, porque la diferencia no apunta para nadie sino que crea el permanente movimiento de diferir. De ese modo, no hay un principio de identidad entre el sujeto y el objeto, ni tampoco en el sujeto ni en el objeto. Cito textualmente algunas líneas de Diferencia y repetición:

Cuando la diferencia es subordinada, por el sujeto pensante, a la identidad del concepto [...] lo que desaparece es la diferencia en el pensamiento, la diferencia de pensar con el pensamiento, la genitalidad de pensar, la profunda rajadura del Yo que sólo lo lleva a pensar pensando su propia pasión y también su propia muerte en la forma pura y vacía del tiempo. Restaurar la diferencia en el pensamiento es deshacer este primer nudo que consiste en representar la diferencia bajo la identidad del concepto y del sujeto pensante (Deleuze, 1988, p. 187).

Quizá este breve recorrido continúe en Derrida quien introdujo la distinción crucial entre diferencia y differènce. La diffèrence sería la anarquía que improvisa, una anarquía portadora de una alteridad que escapa siempre a lo mismo y a lo idéntico. Ese nuevo concepto permite pensar en el proceso de diferenciación, más allá de toda suerte de límites, sean éstos culturales, nacionales, lingüísticos, etc. La diffèrence no es una distinción, una esencia o una oposición, sino un movimiento, una referencia a la alteridad, a una heterogeneidad que no es de modo alguno oposicional.

La decisión acerca de cómo nos encontramos con otros, siendo otros, entre otros, es educativa, política y éticamente educativa. En ese encuentro la diferencia es lo que reúne no lo que distingue, no lo que confina, no lo que domina despóticamente. En 
el encuentro con alguien, ese alguien nunca es igual, siempre difiere, no de algo en particular sino de todo. No hay arquetipo ni homogeneidad ni semblante único:

No sólo toda la gente es diferente, sino que todos difieren -no de nada, sino de otros-. No difieren de un arquetipo o de una generalidad .... En cuanto a las diferencias singulares, no son sólo 'individuales', sino infra-individuales: nunca es a Pedro o a María a quienes encuentro, sino a uno o a otra en tal 'forma', en tal 'estado', en tal 'humor" (Nancy, 2006, p. 24).

El encuentro es con lo inesperado que se mueve hacia otra parte, con lo que difiere de uno, de otro y de ambos; una diferencia que habita entre la planificación y la conmoción, entre lo previsible y el acontecimiento, ese espacio indefinible de la contingencia donde todo puede ocurrir.

\section{La lectura pedagógica de las diferencias}

Como bien se sabe mucho se ha trabajado en las últimas décadas para quebrar la lógica de homogenización y de exclusión que gobernó a las escuelas desde su fundación moderna. La grieta entre la educación común y la educación especial, por ejemplo, ha sido objeto de revisión por parte de las políticas públicas, así como el cuidado por ciertos y determinados grupos sociales, étnicos, lingüísticos, religiosos, etcétera, que no habían sido integrados a la escolaridad general.

Las diferencias, así, se tornaron una cuestión pedagógica de prioridad, a veces condenadas a la óptica estrecha de una relación binaria -exclusión/inclusión, normal/anormal, común/especial- y otras veces siguiendo la perspectiva de un abordaje especializado de individuos particulares al interior de las escuelas regulares. En todos los casos, la pregunta que sobrevive es si las diferencias, así, en plural, fueron comprendidas en los escenarios educativos según un lenguaje estrictamente pedagógico o, bien, si ese lenguaje se ha visto afectado por discursos y dispositivos técnicos, jurídicos, morales, economicistas, politicistas, etcétera.

El origen latino de la palabra diferencia indica una cualidad o un accidente por el cual algo se distingue de otra cosa. Expresa variedad entre cosas de una misma especie. Sugiere una controversia, disensión u oposición de dos o más personas entre sí. Aplicado a la danza y a la música sugiere una diversa modulación, o un movimiento, que se hace en el instrumento, o con el cuerpo, bajo un mismo compás. En su acep- 
ción matemática significa resto, el resultado de la operación de restar.

Sin embargo ¿cuál es el sentido que la diferencia ha asumido o del que se ha apropiado la educación, sobre todo en tiempos en que la "inclusión de los diferentes" a la escuela se ha vuelto razón de Estado? La respuesta parece ser directa, casi sin matices: se asumen las diferencias como diversidad y la diversidad en tanto mención a sujetos o grupos de sujetos vistos como desiguales.

Los significados latinos de la palabra 'diverso' son sorprendentes para la buena conciencia del léxico en vigencia: diverso proviene de ‘opuesto’, ‘enemigo', ‘alejado’. Opuesto al 'nosotros', enemigo de la idea de igualdad y de normalidad. Aquello que está alejado del sendero por el que todos transitamos. Nuestro deber, incluso educativo: reconducir a los alejados al sendero correcto, hacerlos transitar por el mismo camino que pisamos a diario.

Hay aquí, evidentemente, una alteración de sentidos provocado por el pasaje de la diferencia a la diversidad, lo que impulsa a plantear cuatro interrogantes:

1. ¿En qué sentido es posible afirmar que la diversidad configura por sí misma y en sí misma un discurso más o menos completo, más o menos esclarecedor y más o menos revelador acerca del otro, de la alteridad? 0 dicho de otro modo: ¿diversidad está, acaso, en el lugar de alteridad, ocupa -y por lo tanto desocupa- su sentido?;

2. ¿Qué sugiere esa identificación recurrente, insistente, que se produce entre diversidad y pobreza, desigualdad, marginación, sexualidad, extranjería, generación, raza, clases sociales, y, un poco más recientemente, su notorio apego a la discapacidad?;

3. ¿Qué grado de sinonimia o antinomia puede pensarse entre la diversidad y la diferencia?

4. Y por último ¿en qué medida el anuncio y el enunciado de diversidad ofrece una perspectiva de cambio pedagógico? Y además ¿se esfumaría, de ese modo, la separación radical entre lo común y lo especial, no sólo desde el punto de vista de las instituciones, los programas y las poblaciones, sino sobre todo en su dimensión más simbólica?

Da la sensación de que hablar de la diversidad se ha convertido en una suerte de recitado que apunta insistentemente hacia 'otros extraños', en tanto mero ejercicio descriptivo de una determinada exterioridad compulsiva: así, 'ellos' son los diversos, 'ellos' poseen atributos que hay que remarcar y denotar como ‘diversidad'. Si la palabra diversidad no contribuye a borrar de una vez esa violenta frontera que separa el 'nosotros' del 'ellos', estaría yendo entonces en la dirección opuesta, esto es, hacien- 
do de la diversidad un extraño y peligroso exceso de alteridad, de una 'alteridad fuera de la alteridad' o bien: de una 'alteridad todavía más allá de la alteridad'.

La diversidad provoca una inclinación hacia la desigualdad y la mirada hacia el otro se torna especialmente problemática: el otro diverso acaba por ser un otro desigual. En todo caso se ha producido un descuido o un cierto olvido o un encubrimiento o bien un silencio cómplice acerca del sentido del 'nosotros mismos' frente a la idea de diversidad. Si los otros son los diversos y si la diversidad está familiarizada con la desigualdad, la fórmula se cierra perfectamente sobre los demás. Pero ¿y nosotros? ¿no somos, acaso, diversidad? ¿no vivimos, no pensamos, no estamos allí, en esa experiencia de la diversidad?

El abuso del término diversidad podría promover la presencia de un concepto no sólo vacío, sino fundamentalmente vaciado de experiencia. Como aquella profesora que, al interior del estudio sobre los sentidos implicados en la idea de diferencia, mencionado con anterioridad, afirmó, decidida: "yo tengo cuatro diversos en mi clase" -haciendo referencia, luego, a aquellos que siempre se le escapaban al patio(Skliar \& Dussel, 2011).

Por lo tanto ¿qué otra cosa podremos decir de la diversidad si no que, en efecto, ‘hay diversidad’? ¿Qué más hay aparte del dato descriptivo, un golpe de ojos, la memoria presente y evidente que sabe todo el tiempo de las enormes y continuas variaciones humanas que habitamos y nos habitan? ¿Qué más suponer más allá y más acá de la evidencia de que todo escenario humano muestra su diversidad? Tal vez fue Lefebvre (1971), en su Manifiesto diferencialista, uno de los primeros en percibir la necesidad de marcar enfáticamente la distinción necesaria entre los sentidos implicados en la pronunciación de la diversidad y la diferencia:

¿Y la diversidad? No va más allá de una verificación. No capta el paso de la originalidad que pretende ser sustancial y que se cree esencial a la diferencia, a través de las pruebas que esperan todo aquello que proviene de la naturaleza. La palabra 'diversidad' se acomoda a cualquier cosa: guijarros, minerales, niños, flores, vestidos, mujeres. Permite describir, prohíbe la operación metafísica a través de la cual los árboles diversos se identifican a la idea de árbol, los diversos frutos a la idea de fruto, etc., pero su competencia no va más allí (Lefebvre, 1971, p. 45).

La opción que consiste en sostener la idea de diversidad es menos atractiva, más 
publicable pero mucho más decepcionante: la fabricación, la invención de una hipotética e imposible lista que ejemplifique y tipifique la diversidad en todas sus versiones y variaciones. En ese caso habrá siempre seis, siete u ocho ejemplos para dar: diversidad de raza, sexo, generación, edad, género, religión, aprendizaje, lenguas, y enseguida, como un bostezo, como una exhalación desanimada y extenuada, ese profundo, solitario y salvador etcétera que ya no puede ni sabe cómo seguir enumerando la diversidad.

Tal vez el etcétera sea el límite último de la diversidad y a partir de allí comience la alteridad incognoscible, la alteridad per se, el nacimiento de ese otro que, como decía Lévinas, se retira en su misterio, con su misterio:

Lo absolutamente 0 tro, es el 0 tro. No se enumera conmigo. La colectividad en la que digo 'tú' o 'nosotros' no es un plural de 'yo'. Yo, tú, no son aquí individuos de un concepto común. Ni la posesión, ni la unidad del número, ni la unidad del concepto, me incorporan al Otro. Ausencia de patria común que hace del 0tro el extranjero; el extranjero que perturba el 'en nuestra casa'. Pero extranjero quiere decir también libre. Sobre él no puedo poder (Lévinas, 1977, p. 17).

\section{La lectura literaria de las diferencias}

La diferencia es una palabra que ya venimos pronunciando desde hace tiempo, antes, mucho antes, de que se transformara en una palabra-objeto, en una palabra-política, en una palabra-pedagógica, en una palabra-cultural, en una palabra-sin nadie-dentro y sin nadie-del-otro-lado. Pronunciamos esa palabra a partir de algunos indicios filosóficos (por ejemplo en Skliar, 2007) con los cuales nos fue posible entender la diferencia más allá y más acá de sus vaivenes pedagógicos.

"El hombre es un animal que juzga”, decía Nietzsche (1976, p. 173). Y la traición a la diferencia resume toda la cobardía de los hombres, toda su incapacidad por estar en el mundo entre otros, toda esa ignorancia resumida en el arrojar un nombre y esconder la lengua. "Yo lo conozco, dijo él orgulloso antes de empezar con su difamación", escribe Elías Canetti (2005, p. 98). Y ése es el orgullo mayúsculo de los especialistas: conocer y difamar; atribuir esencias y escaparse a los reductos conceptuales de lo mismo; distanciarse hasta volverse indiferentes. Son los que se enojan todo el tiempo con la alteridad del otro y medicalizan, separan y juntan a voluntad, encierran por dentro y por fuera: "Todo hombre que ha decidido que otro es un im- 
bécil o una mala persona se enfada cuando el otro demuestra que no lo es.", dice Nietzsche (2001, p. 37).

Suponer diferencia en unos pero no en otros resulta de un largo ejercicio de violencia. Usar el lenguaje para atrapar, para enclaustrar, para agraviar, para denostar, para empequeñecer, desvirtúa el lenguaje pero, sobre todo, la relación, la vida. Como ya fue dicho, la diferencia no es un sujeto sino una relación. Cuando la diferencia se vuelve sujeto hay allí una acusación falsa y sin testigos, plagada eso sí de discursos autorizados, renovados, siempre actuales, siempre vigilantes y tensos, que acusan al otro por ser lo que no debería ser.

Ahora bien ¿cómo sería posible una lectura literaria que abriera las compuertas a otros sentidos de la diferencia, una lectura no conceptual, no utilitaria, no evaluable ni olvidable inmediatamente después de ser leída?

En el contexto de un seminario de posgrado 3 hemos considerado la posibilidad de pensar detenidamente en aquella expresión tan trillada: "llamar a las cosas por su nombre", en relación a las cuestiones que se nos planteaban sobre identidad, diversidad, diferencia, cultura. ¿Qué querrá decir llamar a las cosas por su nombre? ¿llamarlas por el nombre que le damos? ¿Por la relación que mantenemos con lo que describimos? ¿Habrá un lenguaje que posibilite nombrar y pensar en lo borroso, lo violento, lo perturbador, lo cegador, lo trágico, lo incierto, lo injusto, lo ambiguo, lo indefinible, lo misterioso, etcétera, más allá de las habituales definiciones sociológicas, antropológicas y pedagógicas?

Al lado de la bibliografía oficial añadimos, mezclada, confundida con ella, otro material compuesto por tres novelas del escritor sudafricano J. M. Coetzee - La edad de hierro (edición española de 2002), Vida y época de Michael K (2006) y Esperando a los bárbaros (2007) - a la que consideramos como una literatura de alteridad. Si bien esta expresión es problemática -pues ¿qué literatura no sería de alteridad?- en el caso de las novelas mencionadas de Coetzee hay dos elementos interesantes a distinguir para lo que nos ocupa aquí:

1. La existencia de tres figuras de alteridad -el vagabundo, el deficiente intelectual y los bárbaros- que encarnan buena parte de las percepciones y concepciones más

3. Hago referencia aquí al Seminario de posgrado "Políticas Culturales" dictado al interior de la Maestría en Comunicación y Cultura, de la Facultad de Ciencias Sociales, Universidad de Buenos Aires, durante el período 2006-2012. primitivas de la alteridad;

2. el hecho de que cada una de ellas provoca relaciones de diferencia, es decir, una dimensión de afección que se establece entre esas figuras 
marcadas como "diferentes" y otras figuras humanas que pasan a su lado y que permanecen cerca de ellas o no, estableciendo formas particulares de vínculo que difieren siempre unas de otras y que, también, difieren en su propia interioridad.

¿Qué nos enseñan estas novelas en relación a todo aquello que venimos discutiendo aquí?

En La edad de hierro una anciana -profesora de filosofía, ya jubilada, que vive sola y enferma a la espera de la visita de una hija- ve desde su ventana la llegada amenazante de un vagabundo; su deseo inmediato es el de quitárselo de la vista, una primitiva necesidad que la hace llamar a las autoridades para que "hagan algo con él”. 0, un poco más tarde -cuando percibe que es imposible hacer desaparecer de su mirada al vagabundo- la intención por aproximarse, ofreciéndole trabajos inútiles, casi esclavos. Incluirlo para apaciguar su propio temor por lo desconocido, sentirse en el derecho de opinar sobre la vida del otro:

El olor más desagradable viene de sus zapatos y sus pies. Necesita calcetines. Necesita zapatos nuevos. Necesita darse un baño. Necesita un baño diario. Necesita ropa interior limpia. Necesita una cama, necesita un techo sobre su cabeza, necesita tres comidas al día, necesita dinero en el banco. Demasiado que dar (Coetzee, 2002, p. 47).

La diferencia como diferencia perceptiva: el olor del otro -o el color, o su forma de andar, lo que sea-. La diferencia aquí entendida como lo que le falta y le hace falta. El uno que determina las necesidades del otro. La diferencia como un abismo incomprensible para el Uno. Ese llamar a las cosas por su nombre nada tiene que ver con la exclusión o con la inclusión, esas serían palabras técnicas o jurídicas o incluso morales: se trata, más bien, de la necesidad de conversar, de usar las palabras para poder estar juntos, de hablar sobre aquello que nos pasa. Pero no de cualquier manera: no hay un único modo de estar juntos, estar juntos no significa estar a gusto, estar en armonía, estar en paz: ¿a quién se le ocurriría semejante idea?

En el encuentro subrepticio entre la anciana y el vagabundo, es el vagabundo el que siempre lleva las de perder, porque es el diferente: el diferente para una mirada fija y obsesiva, para una mirada adormecida. Si lo vemos de lejos el vagabundo es una amenaza, un peligro, una alteridad para expulsar de nuestra atmósfera de supuesta tranquilidad. Si lo vemos de cerca, lo único que deseamos es que sea uno de los nuestros, un semejante. Allí no hay relación. Pero si conversamos, si entramos en una 
relación que no tenga el ánimo de hacer del otro una amenaza primitiva o un insulso semejante, quizá la diferencia valga la pena, quizá la diferencia sea lo que mejor narre lo humano.

Y para eso tenemos que tener tiempo. No formas de nombrar: tiempo. No mejores o peores etiquetas: tiempo. Porque cuando no hay tiempo, hay norma. Cuando no hay tiempo, juzgamos. Cuando no hay tiempo, la palabra es la proclamación del exilio del otro, su indigno confinamiento:

Lo cierto es que, si tuviéramos tiempo para hablar, todos nos declararíamos excepciones. Porque todos somos casos especiales. Todos merecemos el beneficio de la duda. Pero, a veces, no hay tiempo para escuchar con tanta atención, para tantas excepciones, para tanta compasión. No hay tiempo, así que nos dejamos guiar por la norma. Y es una lástima enorme, la más grande de todas (Coetzee, 2002, p. 94).

Si no hay tiempo, dijimos, no hay conversación, no hay existencia, no hay presente, no hay relación, no hay diferencia. Lo contrario de la conversación, de la existencia, del presente, de la relación, de la diferencia: la falta de tiempo, es decir, la tiranía de la normalidad, la condena de lo normal.

Decir la diferencia, sí. Escuchar la diferencia. Tener tiempo. El mundo es una inmensa circunferencia agujereada por las excepciones. $Y$ hay demasiadas palabras para ocultar su derrame, las aguas que no se embalsan, los sonidos disfónicos, el caminar rengo, las espaldas vencidas, el aprendizaje curvo, la memoria azarosa, el cuerpo desatento, los oídos mudos, los ojos que miran en una dirección que no conocemos. Igualdad, equidad, diversidad, anormalidad, discapacidad, necesidad, deficiencia, diferencia, desatención, retraso, inmadurez, autismo. El hartazgo del lenguaje que humilla, del lenguaje hipócrita.

Quizá se trate del mismo hartazgo que siente y padece, página a página, Michel K, aquel personaje de labio leporino de Coetzee.

Lo primero que advirtió la comadrona en Michael $\mathrm{K}$ cuando lo ayudó a salir del vientre de su madre y entrar en el mundo fue su labio leporino. El labio se enroscaba como un caracol, la aleta izquierda de la nariz estaba entreabierta. Le ocultó el niño a la madre durante un instante, abrió la boca diminuta con la punta de los dedos, y dio gracias al ver el paladar completo. A la madre le dijo: -Debería alegrarse, traen suerte al hogar (Coetzee, 2006, p. 9). 
En Vida y época de Michael K. el escritor sudafricano Coetzee hace atravesar a Michael -a quien marca física y mentalmente como un ser distinto- por toda una Sudáfrica en guerras, cuya única voluntad es la de esparcir las cenizas de su madre para, enseguida, realizar su viaje de inadvertencias, de ansiado anonimato.

Michael $\mathrm{K}$ se esconde una y mil veces y no logra cumplir con su deseo de no ser perturbado; él preferiría no conversar con nadie, pero es interrumpido por infinitas preguntas, infinitas inquisiciones. Prefiere la soledad, pero siempre hay alguien más que le dirá qué hacer y qué no hacer, cómo ser y cómo no ser.

Se trata entonces de una metáfora sobre la imposibilidad del quitarse, del preferir no estar y no poder, una pesadilla interminable donde nadie parece querer dejarlo en paz. Michael se vuelve un don nadie que está perseguido por incógnitas que otros no pueden soportar para sí; es un ser sin nombre al que nadie dejará de nombrar insistentemente:

Quiero conocer tu historia -escribirá el médico de un internado-. Quiero saber por qué precisamente tú te has visto envuelto en la guerra, una guerra en la que no tienes sitio. No eres un soldado, Michael, eres una figura cómica, un payaso, un monigote .... No podemos hacer nada aquí para reeducarte .... ¿Y para qué te vamos a reeducar? ¿Para trenzar cestas? ¿Para cortar césped? Eres un insecto palo .... ¿Por qué abandonaste los matorrales, Michael? Ese era tu sitio. Deberías haberte quedado toda la vida colgado de un arbusto insignificante, en un rincón tranquilo de un jardín oscuro (Coetzee, 2006, p. 155-156).

El desprecio por Michael K es evidente. Como si el ser diferente fuera sinónimo de sobra, de desperdicio. Como si el diferente no pudiera vivir entre los hombres y debiera quitarse de la vista del mundo. Como si fuera imposible enseñarle algo al diferente. Diferente que ya es considerado como ser-muerto y, a la vez, una presencia insoportable que nos hace testigos involuntarios de otros modos de lenguaje, de comportamiento, de aprendizaje, de vida. Y será el mismo médico del internado quien, al fin, logre describir éticamente a Michael K. Una manera de hacer justicia con aquel que no pretende transformarse en otro diferente al que es, que no desea ni ser mejor ni peor:

Soy el único que ve en ti el alma singular que eres .... Te veo como un alma humana imposible de clasificar, un alma que ha tenido la bendición de no ser contaminada por doctrinas ni por la historia, un alma que mueve las alas en ese sarcófago rígido .... Eres el último de tu especie, un resto de épocas pasadas (Coetzee, 2006, p. 158). 
Si en La edad de hierro se nos enseña sobre todo la existencia de una relación directa entre tiempo y norma y la disolución de la idea de que las relaciones sólo pueden plantearse bajo el binomio de la exclusión-inclusión; si en Vida y época de Michael $K$ lo que surge, entre otras cosas, es la incapacidad nuestra de percibir la singularidad de otro y someterlo siempre al control y la vigilancia, en Esperando a los bárbaros surge la posibilidad de pensar la diferencia entre el lenguaje de la conversación entre diferencias y el lenguaje jurídico que pretende, hoy, regular todo contacto, todo vínculo de alteridad.

En la novela, un juez, ya casi anciano y algo cansado, reside en el juzgado de una pequeña ciudad. Más allá de los muros del poblado, un largo desierto donde se dice que habitan los bárbaros. Todo allí está organizado en función de esa amenaza: las casas con rejas, la cárcel del juzgado preparada para futuras y ciertas reclusiones, policías entrenados para resistir la invasión y un creciente militarismo en ciernes.

Los bárbaros no han sido vistos jamás, pero se cuenta de ellos, se habla de su peligro, de su amenaza. El mito de la existencia de los bárbaros ha pasado de generación en generación y el miedo es aquello que hace respirar a la ciudad. La idea de la presencia de los bárbaros impide, por un lado, una vida normal. Pero por otro lado habilita la materialidad de toda una serie de instituciones de Estado. ¿Existirán los bárbaros, de verdad? La novela de John Maxwell Coetzee deja abierta la sospecha. Quizá no existan y nunca existieron. Pero ya el mito, la ficción y, sobre todo la ley, se han convertido en pura cotidianeidad. Y habrá que sostener el relato desde las instituciones hasta las últimas consecuencias.

Lo cierto es que la novela no trata sobre los bárbaros, sino sobre aquellos que esperan a los bárbaros, lo que es muy diferente. La verdad no es sobre los bárbaros, sino sobre el creciente dolor de la existencia durante la inmensa espera del supuesto enemigo, como lo dice el personaje del juez: “El dolor es la verdad, todo lo demás está sujeto a duda" (Coetzee, 2007, p. 15).

Habría que pensar si es posible evitar o eludir esa obsesión tan actual por la supremacía del lenguaje jurídico y su progresivo refinamiento; ese lenguaje que está ahí, justamente para legislar el orden de las relaciones de convivencia, de alteridad y de diferencia con tal fuerza de ley, que ya parecería no existir otra relación posible que la de uno consigo mismo o, en el mejor de los casos, de uno con otros demasiados próximos, fatalmente parecidos, sospechosamente vueltos semejantes. 
Resulta al menos curiosa la imagen que se ha establecido acerca de la convivencia entre diferencias, sobre todo en ciertos ámbitos plagados de jergoceo jurídico, como aquella que debe acatar sin más ciertas reglas -no siempre formuladas o apenas sí entredichas- que instalan de una vez la idea de una supuesta empatía, calma y no-conflictividad. La insistencia de la razón jurídica, aún en su parco pero comprensible utilitarismo y por su intención de traducir algunos fragmentos de la vastedad de las relaciones de convivencia, no puede ser sino una desembocadura estrecha donde se prende y aprehende el movimiento inasible de lo humano; movimiento que, entonces, comienza a aquietarse, a estancarse. Lo político de la convivencia queda, como dice Jean-Luc Nancy, irremediablemente partido en dos: "Por un lado la abstracción formal del derecho que ... 'da derecho' ... a toda particularidad y toda relación” (Nancy, 2006, p. 63). En efecto, da la sensación de que ese derecho no tiene derecho a otra cosa, no puede pretender otro sentido, a no ser, claro está: ... que el derecho mismo trate de erigirse como origen o fundamento, bajo los casos de una Ley absoluta" (Nancy, 2006, p. 63).

Si la razón jurídica se configura con antelación y en anteposición a los lenguajes de la convivencia, su vitalidad quedaría subordinada y sepultada a unas pocas fórmulas atiborradas de prescripciones, excepciones y obligaciones. Sin embargo, el saber experiencial de la relación parece decir otra cosa bien diferente: que su contingencia original está cimentada en la vulnerabilidad, el conflicto, la fragilidad, el desencuentro, la perturbación, la alteración, la interrupción, lo finito, la hospitalidad, lo intocable, la hostilidad, lo otro, su misterio, la irreductibilidad. De esa tensión entre razón jurídica y saber relacional, pareciera ser que la norma defiende su norma en el mismo momento en que pretende iniciar su mandato y todo parece ocurrir como si alguien, antes de afectar o de sentirse afectado por un otro, deba hacerse la pregunta obligada acerca del derecho por sentirse de ese modo y justificar, con primordial anticipación, si con ello no se lesiona, no se hiere o si se violenta algún principio (jurídico) de la individualidad.

La eficacia de la razón jurídica alcanza, así, su mayor plenitud y su más ansiado anhelo: en la pregunta por el derecho y en las obligaciones de la convivencia está la diseminación misma de la norma; la aplicación de una norma que, como dice Giorgio Agamben: "No está en modo alguno contenida en ella, ni tampoco puede ser deducida de ella, porque de haber sido así, no habría sido necesario crear todo el imponente edificio del derecho procesal" (Agamben, 2005, p. 83). 
Es posible que asistamos a un tiempo de supremacía de la razón jurídica y/o del exceso del lenguaje jurídico por encima de otros lenguajes y de otros modos de convivencia, pero no es sólo ello lo que condiciona la pérdida de la responsabilidad de la relación ética. Este tiempo obsceno, al decir de Joan-Carles Mèlich (1998), ha transformado dramáticamente la ética en política o sociología y ha convertido la relación con el otro en un poder que lo esclaviza, amenazando así su fin, el fin de la ética.

Pero mal haríamos en pensar que el jergoceo, el exceso de razón juridíca y la diseminación de la ley, anterior y amenazante de la ética, son males apenas de esta época. Ya Michel de Montaigne se interrogaba sobre la discrepancia entre nuestro lenguaje común y lo que él llamaba como arte del lenguaje leguleyo:

Porque los príncipes de ese arte se aplican con particular atención a elegir palabras solemnes y formar cláusulas compuestas con arte, y así tanto pesan cada sílaba y de tal manera retuercen las conexiones, que se enmarañan y abisman en la infinidad de sus figuras y particiones, con lo que ya no pueden entrar en regla ni prescripción alguna, ni en ninguna inteligencia cierta (Montaigne, 2007, p. 48).

\section{Conclusiones}

¿Qué puede aportar una mirada filosófica y literaria a una probable idea -aunque difusa- de una pedagogía de las diferencias?

En primer lugar, que las diferencias no son el carácter negativo de la identidad, su contracara velada y, por lo tanto, una cualidad de la cual un individuo deba despojarse para poder "ser-aprender como los demás". Por el contrario, se trataría de un movimiento que está en medio de una relación, que la hace diferir de sí misma y de otras relaciones, y que plantea un escenario que considera la singularidad del vínculo pedagógico al interior de una proposición inicial de igualdad -pero no de equivalencia-.

En segundo lugar, y en consonancia con lo anterior, que las diferencias no son atributos esenciales de individuos sino de relaciones; puntos de partida para hacerse presente en las prácticas pedagógicas no ya bajo la humillación de la exclusión o la pretensión de la inclusión, sino de una conversación sobre "aquello que nos pasa y hacemos" al interior de las instituciones educativas.

De este modo habrá que pensar si el educador que presta atención a las diferencias no es aquel que se hace presente de otra manera a la hora de educar. $Y$ es que si no estamos presentes ninguna percepción ni ninguna relación de y entre 
diferencias pueden hacerse posibles. ¿Pero qué significa estar presentes sino estar atentos, escuchar abiertos a la conversación, pero también estar tensos, algo desnudos y sin saber cómo llamar a las cosas por su nombre, con eso que nos pasa en el presente?

Estar presentes podría significar que nuestra presencia -es decir nuestro cuerposiente, padece; que esa presencia no puede postergarse ni hacia atrás ni hacia delante: se trata de un aquí y un ahora que podría ser ancho y largo pero que no puede ser ni antes ni después; que estar presente supone la debilidad o la fragilidad de un "yo" centrado en sí mismo, egoísta, encerrado; que la presencia es presencia plural, presencia entre varios, entre muchos, entre cualquiera, entre desconocidos; que, también, otra presencia entra en la nuestra, a veces hace nido, otras veces atropella, otras tantas pasa desapercibida y otras se vuelve, casi por azar, presencia esencial. Estar entre diferencias es, siguiendo una metáfora literaria, estar entre desconocidos. Decía Elías Canetti (1980, p. 173): “Lo más importante es hablar con desconocidos. Pero hay que ingeniárselas para que ellos hablen, y el papel de uno es hacerles hablar. Cuando esto resulta imposible, ha empezado la muerte".

Los desconocidos encarnan una verdad posible, aparente, sencilla, que está quizá en la punta de nuestra lengua. Lo contrario de aquellos que nos imponen su voz, la sobreponen a toda costa, exponen su punto de vista como si se tratara en efecto del mundo en sí mismo, nos retuercen con su estridencia, con ese barullo y tumulto de palabras que de tanto sonar ya no suenan ni resuenan.

Los nombres que atribuimos a otros nunca se dirigen a los otros. Los damos, pero no se los damos. No los ofrecemos: los instalamos. Son nombres que nombran a los demás pero que no los llaman. No los convocan a venir, sino a quedarse quietos. Ninguna definición ha cambiado radicalmente una relación. Son nombres para usar entre pares y volver a separar, una y otra vez, a los supuestos impares. Se usan con vehemencia pero nadie se ensucia las manos ni se entierra los pies. Describen lo que sería el otro, si el otro estuviese quieto, aquietado, ajustado a unos ojos que se pertrechan detrás de la apariencia civilizatoria de una idea.

¿Cómo nombrar la diferencia? ¿qué nombre darle si cada nombre ya fue dado y es ése: el de cada uno? ¿cómo nombrar la diferencia sin aproximarse? ¿Es posible una conversación que no esté presente, en la igualdad más generosa del inicio y en la ternura más extrema e intensa de nuestras diferencias? Tal vez este fragmento de Coetzee lo exprese de una manera aún más directa: 
¿Habría sido mejor si hubiéramos seguido viviendo como hermano y hermana, o huésped y anfitrión, o como amo y criado, o lo que hasta entonces hubiésemos sido? .... En un mundo de azares, ¿es que eran venturosos unos y funestos otros? Nos rendimos al abrazo de un desconocido o nos arrojamos a las olas; en un abrir y cerrar de ojos nuestra vigilancia se relaja; nos quedamos dormidos; y al despertar nos encontramos con que hemos perdido el rumbo de nuestras vidas. ¿Qué son esos parpadeos contra los que la única defensa posible sería una vigilia tan constante como inhumana? ¿No serán tal vez las grietas e intersticios por los cuales otra voz, otras voces hablan a nuestras vidas? ¿Con qué derecho les cerramos nuestros oídos? (Coetzee, 2004, p. 25). 


\section{Referencias bibliográficas}

Agamben, G. (2005). Estado de excepción. Buenos Aires: Adriana Hidalgo.

Canetti, E. (1980). La lengua absuelta. Barcelona: Muchnik Editores.

Canetti, E. (2005). Obra completa, volumen IV - Apuntes, 1942-1993. Barcelona: Galaxia Gutenberg.

Coetzee, J. M. (2002). La edad de hierro. Barcelona: Literatura Mondadori.

Coetzee, J. M. (2004). Foe. Barcelona: Literatura Mondadori.

Coetzee, J. M. (2006). Vida y época de Michael K. Barcelona: Literatura Mondadori.

Coetzee, J. M. (2007). Esperando a los bárbaros. México: Random House Mondadori.

Deleuze, G (1988). Diferencia y repetición. Barcelona: Júcar Universidad.

Lefebvre, H. (1971). Le manifeste différentialiste (Collection Idées). París: Gallimard.

Lévinas, E. (1977). Totalidad e Infinito. Salamanca: Sígueme.

Mèlich, J.-C. (1998). El tiempo y el deseo. Nota sobre una ética fenomenológica a partir de Lévinas. Enrahonar, 28, 191-192.

Montaigne, M. (2007). De la experiencia y otros ensayos. Barcelona: Ediciones Folio.

Nancy, J.-L. (2006). Ser singular plural. Madrid: Arena Libros.

Nietzsche, F. (1976). Más allá del bien y del mal. Madrid: Alianza Editorial.

Nietzsche, F. (2001). Todos los aforismos. Buenos Aires: Leviatan.

Skliar, C. (2007). Derrida e Educação. Belo Horizonte: Autêntica.

Skliar, C. \& Dussel, I. (2011). From equity to difference: educational legal frames and inclusive practices in Argentina. In A. J. Artiles, E. B. Kozleski, \& F. R. Waitoller. Inclusive education. Examining equity on five continents. Massachussets: Harvard University Press.

Veiga-Neto, A. (2009). Nietzsche y Wittgenstein: herramientas para pensar la diferencia y la Pedagogía. Mutatis Mutandis, 2(1), 122-133.

Submetido à avaliação em 24 de julho de 2014 e aprovado para publicação em 25 de novembro de 2014. 